\title{
POST DISCHARGE OUTCOME OF PRETERM INFANTS IN A LOW-MIDDLE- INCOME COUNTRY
}

\author{
Evelyn Mungyeh Mah ${ }^{1,2}$, Naiza Ngowo Monono, ${ }^{1,3}$, Daniel Armand Kago Tague ${ }^{1,2}$, Seraphin Nguefack $^{1,2}$, \\ Isabelle Mekone Nkwele ${ }^{1}$, Dany Hermann Ngwanou ${ }^{1}$, Hubert Desire Mbassi Awa ${ }^{1,4}$, Andreas Chiabi ${ }^{1,2}$, \\ F Angwafo III Fru' ${ }^{1,2}$. \\ ${ }^{1}$ Department of Pediatrics, Faculty of Medicine and Biomedical Sciences, University of Yaoundé, Yaounde, \\ Cameroon; \\ ${ }^{2}$ Department of Pediatrics, Faculty of Medicine and Biomedical Sciences, Yaoundé Gynaeco-Obstetrics and \\ Pediatrics Hospital, Yaounde, Cameroon; \\ ${ }^{3}$ Faculty of Health Sciences, University of Buea, Buea, Cameroon, ${ }^{4}$ Mother and Child Centre of the \\ Chantal Biya Foundation, Yaounde, Cameroon.
}

\begin{abstract}
Background: The improvement of postnatal care has led to the increase in survival rate of preterm infants in our setting and considering their vulnerability, we set out to assess the morbidity and mortality of preterm infants 12 months after discharge from the neonatal intensive care unit (NICU).

Methods: A retrospective cohort study was done from the 2008 to 2013 at the Yaoundé Gynaeco-Obstetric and Pediatric Hospital and included children born preterm, admitted in the NICU and discharged alive during the study period. Results: Out of 816 premature infants that were discharged alive from the NICU, only $232(28.4 \%)$ preterm infants discharged alive presented for the routine visits during the first 12 months of life. Among these, 206 (89\%) had at least one complication during the neonatal hospitalization period. Postnatal complications were significantly more frequent in infants born before 34 weeks of gestation and in babies with birth weight below 1500 grams $(p<0.001)$. Up to $72.5 \%$ of those who came for routine visits were less than 34 weeks and $86 \%$ weighed $<2000 \mathrm{~g}$ at birth. Seventy-six $(32.7 \%)$ preterm infants were readmitted within their first year of life and the causes of readmission were respiratory tract diseases in 42 (55\%), late neonatal sepsis in $19(25.0 \%)$, malaria in $9(11.8 \%)$ and epilepsy in $6(7.9 \%)$. Neither the gestational age nor birth weight influenced readmission $(p=0.25, p=0.590$ respectively). The smaller the gestational age, the longer the duration of postnatal hospitalization $(p<0.001)$.

Conclusion: Routine follow-up after discharge remains a problem in our setting due to non-respect of appointments. Infants born preterm suffer mostly from respiratory tract diseases during the first year of life.
\end{abstract}

\section{Introduction}

Preterm birth remains a global problem especially in developing countries. It is a major determinant of neonatal mortality and morbidity ${ }^{1,2}$ and the morbidities associated with preterm often extend to later life, resulting in enormous physical, psychological and economic costs. ${ }^{3}$ With the increase in preterm birth rate, infants born at the lower limit of viability have the highest rates of all complications and the highest

Address for Correspondance: Daniel Armand Kago Tague, Department of Pediatrics, Faculty of Medicine and Biomedical Sciences, University of Yaounde I, Cameroon. Gynaeco-Obstetrics and Pediatric Hospital, 4362 Route de Ngousso Yaounde -Cameroon.

Email: kagog2@yahoo.fr

C2021 Pediatric Oncall

\author{
ARTICLE HISTORY \\ Received 21 February 2021 \\ Accepted 2 April 2021
}

\section{KEYWORDS}

Post discharge, morbidity, preterm infants mortality rates. 4,5 The mortality rate for preterm infants and the gestational age-specific mortality rate have dramatically improved over the last decades, due to improvement in postnatal care provided in delivery rooms and neonatal intensive care units. Despite these improvements infants born preterm remain vulnerable to a wide range of complications, not only in the neonatal period, but also in the long term. ${ }^{4,6}$ Recently interest has shifted from identifying the incidence of in hospital morbidity and mortality to long-term morbidities in childhood.

In our setting the improvement of postnatal care has also led to the increase in survival rate of preterm infants. ${ }^{4,7}$

In the care of preterm infants, the immediate goal is survival; the ultimate goal is intact survival, which is survival without morbidity. Much is known on the outcome of preterm infants after discharge in developed 
countries but very little is known about what happens to these infants in developing countries like Cameron after discharge from hospital.

With the increasing number of surviving preterm infants and considering their vulnerability to develop various morbidities, we set out to examine the health situation of preterm infants after discharge from the neonatal unit of the Yaoundé Gynaeco-Obstetric and Pediatric Hospital (YGOPH) with the goal of assessing the morbidity and mortality of preterm infants after discharge in order to propose strategies to prevent and manage them.

\section{Methods \& Materials}

This was a retrospective cohort study. We obtained authorization for research from the YGOPH Institutional Ethical Committee for Human Health Research and informed consent was obtained from the parents of the children. Data collected from files was confidential. We reviewed medical records of the preterm neonates who were hospitalized in the NICU from the $1^{\text {st }}$ of January 2008 to $30^{\text {th }}$ of June 2013 and were discharged from the unit alive and followed up in the hospital for at least 1 year after discharge or were rehospitalized for one reason or the other. All patients discharged from the NICU after a period of hospitalization, are followed up at the outpatient unit. The preterm infants have a precise schedule of follow up depending on the gestational age. For the extreme and very preterm, post discharge follow up is done weekly while for the late preterm infants follow up is done 2 weeks immediately after discharge respectively, then monthly for 6 months, every 3 months for the next 6 months and finally every 6 months. The clinical assessment of the preterm infants on follow up consisted of a semi-structured interview with the parents and a complete clinical examination noting the anthropometric parameters and signs of disease. We also collected the files of all preterm infants rehospitalized during the study period from all the units of the pediatric service. The following information was extracted from the files: gestational age, birth weight, gender, duration of hospitalization, morbidities during hospitalization in NICU, causes of readmission after discharge from the neonatal unit and outcome of readmission. Concerning the mothers, the following parameters like age, educational level, profession and marital status were retrieved.

The estimated sample size was calculated using the Cochran's formula. Considering the prevalence of prematurity at the neonatology unit of the YGOPH to be $26.5 \%$ and the percentage of preterm who survived during this same period at $63.4 \%$ in $2012^{4}$ a precision of 0.05 and the confidence interval as 1.96 , the minimal sample size was 215 preterm infants.

\section{Statistical analysis}

Data analysis was done using the SPSS 9.0 and Microsoft excel 2007 software. The quantitative variables were presented using means and standard deviations when the distribution was normal. The relationship between variables were compared using the Chi-square or Fisher's exact test where applicable while the Spearman Correlation Rank (R) was used to establish a correlation between two ordinal qualitative variables. For all tested hypotheses, the statistical significance level of $p$ value was $<0.05$, the confidence interval was $95 \%$ and $R$ varied between -1 and 1 .

\section{Results}

During our study period, 816 premature infants were discharged alive. Of these, $232(28.4 \%)$ followed up for at least 12 months, $104(12.7 \%)$ respected two appointments, $416(50.9 \%)$ honored a visit after discharge and $64(7.8 \%)$ did not return. During their hospital stay in the neonatal period, 206 children $(88.8 \%)$ presented at least one complication. These included jaundice (75.6\%), severe anemia (29.3\%), respiratory distress (25.9\%), hypothermia on admission $(11.2 \%)$, nosocomial infections $(8.6 \%)$ and apnea $(1.7 \%)$. Postnatal complications were significantly more frequent in infants born before 34 weeks of gestation and in babies with birth weight below 1500 grams (Table 1). Total 176 (76\%) of the infants spent less than 1 month in the hospital after birth and only 56 $(24 \%)$ stayed longer than a month. The smaller the gestational age, the longer the duration of postnatal hospitalization (Table 4). Seventy-six (32.7\%) preterm infants were readmitted within their first year of life. Two very preterm babies died from severe anemia. The most frequent causes of readmission were diseases of the respiratory tract in $42(55.3 \%)$ of the readmitted cases, late neonatal infection in $19(25.0 \%)$, malaria in $9(11.8 \%)$ and epilepsy in $6(7.9 \%)$. The incidence of readmission did not depend on the gestational age and birth weight of the infant (Table 1 ). Respiratory tract pathologies were the most frequent cause of readmission, affecting mostly infants with gestational ages between 28 to $<32$ weeks. (Table 2 and 3 ). Fourteen $(6 \%)$ preterm infants were readmitted more than once for respiratory tract illnesses.

Regarding the socio-demographic characteristics of our population, the male: female ratio was 1.15 . Almost all the mothers $(96.9 \%)$ were between 20 and 39 years old with an average age of $29 \pm 5.4$ years, $69 \%$ were single and $52 \%$ were housekeepers.

\section{Discussion}

Routine follow-up of premature infants after discharge from hospital is an important but difficult issue for developing countries due to many factors, such as the establishment of our health care system, the lack of personnel and the difficulty for parents of these children to understand the rationale for continuous follow-up of apparently healthy babies, as well as financial difficulties.

Our conclusions may be skewed by the fact that many premature babies who left hospital alive were lost to follow-up. They could have been readmitted to other health care facilities. It was not possible to track these patients because many records did not have contact numbers and some patients had moved or changed phone numbers. However, the results presented show our reality.

It was not possible to clearly attribute the different morbidities presented by these infants directly to their preterm birth, because we focused only on preterm infants and some of the morbidities could also occur in term infants. 
Table 1. Postnatal complications and readmission of preterm neonates

\begin{tabular}{|c|c|c|c|c|c|c|c|}
\hline & \multicolumn{4}{|c|}{ Neonatal profile } & $\mathbf{R}$ & $\mathrm{CI}_{95}$ & p value \\
\hline & \multicolumn{4}{|c|}{ Gestational age (Weeks) } & & & \\
\hline & {$[22-28] n=12$} & {$[28-32] n=96$} & {$[32-34] n=60$} & {$[34-37] n=64$} & & & \\
\hline Complications & $12(100 \%)$ & $94(97.1 \%)$ & $56(93.3 \%)$ & $44(68.8 \%)$ & -0.35 & $\begin{array}{l}-0.5 \text { to } \\
-0.18\end{array}$ & $<0.001$ \\
\hline \multirow[t]{3}{*}{ Re-admission } & 0 & $44(45.8 \%)$ & $20(33.3 \%)$ & $12(18.8 \%)$ & & & 0.251 \\
\hline & \multicolumn{4}{|c|}{ Birth weight (gm) } & & & \\
\hline & $<1000 n=7$ & $\begin{array}{l}{[1000-1500]} \\
n=109\end{array}$ & $\begin{array}{l}{[1500-2500]} \\
n=107\end{array}$ & $>2500 n=9$ & & & \\
\hline Complications & $7(100 \%)$ & $107(98.2 \%)$ & $87(81.3 \%)$ & $5(55.6 \%)$ & -0.31 & $\begin{array}{c}-0.46 \text { to } \\
-0.13\end{array}$ & 0.004 \\
\hline Re-admission & $4(57.1 \%)$ & $42(38.5 \%)$ & $30(28.0 \%)$ & $0(0.0 \%)$ & & & 0.590 \\
\hline
\end{tabular}

Table 2. Causes of readmission with respect to gestational age.

\begin{tabular}{|c|c|c|c|c|c|}
\hline \multirow{2}{*}{ Causes of re-admission } & \multicolumn{4}{|c|}{ Gestational age (weeks) } & \multirow[t]{2}{*}{ p value } \\
\hline & {$[22-<28] n=12$} & {$[28-<32] n=96$} & {$[32-<34] n=60$} & {$[34-<37] n=64$} & \\
\hline Epilepsy/West syndrome & 0 & 0 & $2(3 \%)$ & $4(6.3 \%)$ & 0.586 \\
\hline Late neonatal infection & 0 & $6(6.3 \%)$ & 0 & $4(6.3 \%)$ & 0.792 \\
\hline Malaria & 0 & 0 & $48(80 \%)$ & 0 & 0.166 \\
\hline Respiratory tract disease & 0 & $38(39.6 \%)$ & $6(10 \%)$ & $4(6.3 \%)$ & 0.088 \\
\hline
\end{tabular}

Table 3. Distribution of the causes of readmission with respect to birth weight

\begin{tabular}{llllll}
\hline \multirow{2}{*}{ Causes of re-admission } & \multicolumn{4}{c}{ Birth Weight $(\mathbf{g})$} \\
\cline { 2 - 6 } & $<1000(\mathrm{n}=7)$ & $\begin{array}{l}1000-1499 \\
(\mathrm{n}=109)\end{array}$ & $\begin{array}{l}1500-2500 \\
(\mathrm{n}=107)\end{array}$ & $>2500(\mathrm{n}=9)$ & $\mathrm{p}$ value \\
\hline Epilepsy/West syndrome & 0 & $2(1.8 \%)$ & $4(3.7 \%)$ & 0 & 1.00 \\
Respiratory tract illness & $4(57.1 \%)$ & $30(27.5 \%)$ & $14(13.1 \%)$ & 0 & 0.517 \\
Digestive tract infection & 0 & $6(5.6 \%)$ & $2(1.9 \%)$ & 0 & 0.714 \\
Late neonatal infection & 0 & $4(3.7 \%)$ & $6(5.6 \%)$ & 0 & 1.000 \\
Malaria & 0 & 0 & $4(3.7 \%)$ & 0 & 0.563 \\
\hline Total & $4(57.1 \%)$ & $42(38.5 \%)$ & $30(28 \%)$ & 0 & 76 \\
\hline
\end{tabular}

Table 4. Duration of hospitalization with respect to gestational age

\begin{tabular}{llllll}
\hline & $\begin{array}{l}\mathbf{2 2} \text { to }<\mathbf{2 8} \\
\text { wks }(\mathbf{n = 1 2})\end{array}$ & $\begin{array}{l}\mathbf{2 8} \text { to }<\mathbf{3 2} \\
\text { wks }(\mathbf{n = 9 6})\end{array}$ & $\begin{array}{l}\mathbf{3 2} \text { to }<\mathbf{3 4} \\
\text { wks }(\mathbf{n = 6 0})\end{array}$ & $\begin{array}{l}\mathbf{3 4} \text { to }<\mathbf{7 4} \\
\text { wks }(\mathbf{n = 6 4})\end{array}$ & p value \\
\hline$<1$ month & 0 & $54(56.3 \%)$ & $58(96.7 \%)$ & $64(100 \%)$ & $<0.001$ \\
$1-2$ months & $12(100 \%)$ & $42(43.8 \%)$ & $2(3.3 \%)$ & 0 & 6 \\
\hline
\end{tabular}

The average age of the mothers in our study was similar to that of Folquet ${ }^{8}$ and Chiabi $^{7}$ who found that $76.4 \%$ of the mothers of premature babies were between 20 and 34 years old. Most publications reveal that low and high maternal ages are the main risk factors for prematurity. ${ }^{9,10}$ All mothers in the study population were of childbearing age, but other factors such as marital status and occupation influenced preterm births, as the literature shows. ${ }^{9,10}$

Most of the women (69\%) were single, which is consistent with most studies. This single-mother status is a predisposing factor for preterm birth ${ }^{4,9}$ and may contribute to non-compliance with follow-up appointments. 
Like most studies, we found that the main short-term complications of prematurity in the neonatal period were jaundice, anemia, respiratory distress and infections. ${ }^{11,12,13}$ We noted that the closer to 37 weeks gestational age (GA), the less acute the neonatal conditions as reported by other authors. ${ }^{13,16}$ This hypothesis was tested when the frequency of complications was compared with GA $(p<0.001)$ and birth weight $(p=0.004)$.

Nearly three-quarters of infants spent less than a month in hospital after birth. Length of hospitalization was inversely related to gestational age and birth weight ( $p$ value $<0.001$ ). These results are similar to those of Leone et $\mathrm{al}^{13}$ who found that the lower the gestational age, the longer the length of hospitalization. Premature infants have more complications, and take longer to achieve complete feeds and thermoregulation autonomy. ${ }^{11}$

In our study, we found a high rate of loss to followup as Folquet reported 25\% loss to follow-up at 12 months of age ${ }^{8}$, which is contrary to the findings of Cooper in Soweto ${ }^{17}$ and Monset-Couchard in Mauritius ${ }^{18}$, who found $10.6 \%$ and $5.4 \%$ loss to follow-up at 12 months of age, respectively. The high rate of loss to follow-up in our study could be explained by several factors: our hospital being a level II referral center in the capital city, receives newborns from all over the country. Upon discharge from hospital, these children should be referred to the health centers closer to their locality for further follow-up, but this system of referral and counter-referral is not yet well implemented in our health system Other reasons could be socio-economic (transportation costs, consultation fees, lack of insurance to cover expenses) and psychosocial (visiting witch doctors and traditional practitioners rather than conventional medicine when babies are sick). Parents in developing countries like Cameroon are very often satisfied with their child's weight gain and do not see the need for follow-up. These questions need to be answered if we want to improve the rate of routine outpatient visits in our context. In developed countries, the financial aspects is thought to be minimized by health insurance policies, a well-planned follow-up network system in hospitals, and home visits that are not available in our context.

After discharge, we found that most of the children who returned for follow-up consultations were either born at a GA less than 34 weeks $(72.5 \%)$ or weighed less than $2000 \mathrm{~g}$ at birth (86\%). It was mostly this group of children who had complications during the neonatal period and in hospital. This could have motivated parents to keep appointments for fear of further complications and, on the other hand, to ensure early detection and management of complications should they occur. This is especially true in the very preterm and extreme preterm infants in whom parents spent much more financially, emotionally and physically for their survival. This may explain why their mothers respected follow-up appointments more than older babies.

During the first year of life, a quarter of the former premature babies were readmitted, Folquet et al observed a readmission rate of $30 \% .^{8}$ Respectively
$29.1 \%$ and $30.1 \%$ premature infants were rehospitalized (at least once) in 1997 and 2002 (38.2\% in Epipage Cohort). ${ }^{19}$ This figure is higher than that reported by Escobar who had an overall readmission rate of $2.72 \% .{ }^{20}$

Among the causes of readmission, respiratory tract diseases $(20.7 \%)$, late neonatal sepsis $(4.3 \%)$ and digestive tract disorders $(3.4 \%)$ were the most frequent. These results are similar to those of Doyle and Brissaud ${ }^{19}$ who also indicated that respiratory diseases were the main cause of hospital readmission in premature infants and several factors correlated with an increase risk of rehospitalization: birth weight less than $1000 \mathrm{~g}$, chronic lung disease and gestational age less than 28 weeks at birth. Our figures were lower than those of the authors working on the extreme preterm group $21,22,23,24$

The literature tells us that the incidence of readmission is generally dependent on gestational age and low birth weight. This was not the case in our study. ${ }^{25}$ The younger the infant, the greater the vulnerability, which may explain why extremely preterm and very preterm infants have a higher readmission rate.

By comparing each cause of readmission with gestational age, we found that airway diseases were the most common cause of readmission and that very preterm infants were the most affected. Infants born at gestational age less than 28 weeks were not readmitted to hospital. Very few survived beyond the postnatal hospitalization period. The results are similar to those of Patel ${ }^{11}$ who found that airway disease, particularly bronchopulmonary dysplasia, was the second leading cause of morbidity in extremely preterm infants. Preterm birth results in the loss of months of fetal development, leaving the infant vulnerable to morbidities, many of which are unique to the preterm population, including bronchopulmonary dysplasia, severe brain damage and severe retinopathy of prematurity. ${ }^{11,24,26}$

We noted a few cases of epilepsy that could be considered as squeal of prematurity. The prevalence of sequelae increases with the shortening of the birth term. ${ }^{27} \mathrm{~A}$ better census of all the early developmental characteristics during the various appointments would allow early detection of these characteristics.

There were $2(0.9 \%)$ deaths in the first two weeks after discharge. These children died of severe anemia, which could have been prevented with closer follow-up and perhaps the use of erythropoietin together with iron. This protocol was not yet part of our practice because of it's cost; it is very expensive for parents who for the most part do not have health insurance. Geeta et $\mathrm{al}^{28}$ found that children born prematurely are more likely to die during the neonatal and early childhood period than children born at term, and that mortality rates increase in proportion to the decrease in gestational age or birth weight. Marilee et $\mathrm{al}^{15}$ reported a mortality rate of $61 \%$ from birth to 6 months of chronologic age. While Copper et al $^{29}$ recorded a mortality rate of $13.3 \%$ before one year of corrected age. Not all infants discharged from hospital were followed up in our health facility and could have been treated elsewhere. This should explain the differences between our results and 
those of the authors above.

\section{Conclusion}

Less than $30 \%$ of preterm infants respected the post discharge follow-up appointments during the first 12 months of life, and $25 \%$ of these preterm infants were readmitted with respiratory tract diseases. The post discharge morbidities did not correlate with the gestational age nor the birth weight.

\section{Acknowledgement}

We thank parents of the patients for participating in the study.

\section{Compliance with Ethical Standards \\ Funding: None \\ Conflict of Interest: None}

\section{References:}

1. Chawanpaiboon $S$, Vogel $J P$, Moller $A B$, Lumbiganon $P$, Petzold $M$, Hogan D et al. Global, regional, and national estimates of levels of preterm birth in 2014: a systematic review and modelling analysis. Lancet Glob Heal. 2019;7:e37-46.

2. Huddy CLJ, Johnson A, Hope PL. Educational and behavioural problems in babies of 32-35 weeks gestation. Arch Dis Child Fetal Neonatal. 2001;85 F23-F28

3. Beck S, Wojdyla D, Say L, Betran AP, Merialdi M, Requejo $\mathrm{JH}$ et al. The worldwide incidence of preterm birth: $A$ systematic review of maternal mortality and morbidity. Bull World Health Organ. 2010;88:31-38.

4. Chiabi A, Mah EM, Mvondo N, Nguefack S, Kamga $\mathrm{KK}$, Mboudou E, et al. Risk factors for premature births : a cross-sectional analysis of hospital records in a Cameroonian health facility. Afr J Reprod Health. 2013;17:77-83.

5. Wen SW, Smith G, Yang Q, Walker M. Epidemiology of preterm birth and neonatal outcome. Semin Fetal Neonatal Med. 2004;9:429-435.

6. Nguefack S, Ananfack EG, Mah E, Kago D, Tatah S, Puepi $Y$ et al. Psychomotor Development of Children Born Premature at the Yaounde Gynaeco-Obstetric and Pediatric Hospital (Cameroon). Open J Pediatr. 2020;10:147-158.

7. Mah EM, Chiabi A, Tchokoteu FL, Nguefack S, Bogne JB, Siyou $\mathrm{H}$ et al. Neonatal mortality in a referral hospital in Cameroon over a seven year period: Trends, associated factors and causes. Afr Health Sci. 2014;14:985-992.

8. Folquet Amorissani, Dainguy E, Kouakou C, Traore B, Houenou Agbo Y, Kouame Konan J. Suivi ambulatoire du prématuré au cours de la première année de vie. In: Archives de Pédiatrie $2008 ; 15: 990$.

9. Smith LK, Draper ES, Manktelow BN, Dorling JS, Field DJ. Socioeconomic inequalities in very preterm birth rates. Arch Dis Child Fetal Neonatal. 2007;92:11-14

10. Thompson JMD, Irgens LM, Rasmussen $S$, Daltveit AK. Secular trends in socio-economic status and the implications for preterm birth. Paediatr Perinat Epidemiol. 2006;20:182-187.

11. Patel RM. Short- and Long-Term Outcomes for Extremely Preterm Infants. Am J Perinatol. 2016;33:318-328

12. Bhatt D, White R, Martin G, Van Marter LJ, Finer N, Goldsmith JP, et al. Transitional hypothermia in preterm newborns. J Perinatol. 2007;27:45-47

13. Leone A, Ersfeld P, Adams M, Meyer Schiffer P, Bucher
$\mathrm{HU}$, Arlettaz R, et al. Neonatal morbidity in singleton late preterm infants compared with full-term infants. Acta Paediatr. 2012;101: e6-10.

14. Wilkinson D, Connolly C, Stirling S. Impact of prematurity on admissions to the neonatal nursery of a rural South African district hospital. J Trop Pediatr. 1999;45:76-80.

15. Allen MC, Donohue PK, Dusman AE. The Limit of Viability - Neonatal Outcome of Infants Born at 22 to 25 Weeks' $^{\prime}$ Gestation. N Engl J Med. 1993;329:1597-1601.

16. Berger TM, Roth-Kleiner M. Enfants nés à la limite de la viabilité : expérience suisse. Arch Pediatr. 2016;23:944950.

17. Cooper PA, Sandler DL. Outcome of very low birth weight infants at 12 to 18 months of age in Soweto, South Africa. Pediatrics. 1997;99:537-544.

18. Monset-Couchard M, De Bethmann O, Kastler B. Mid- and long-term outcome of 166 premature infants weighing less than $1,000 \mathrm{~g}$ at birth, all small for gestational age. Biol Neonate. 2002;81:244-254.

19. Brissaud O, Babre F, Pedespan L, Feghali H, Esquerré $F$, Sarlangue J. Réhospitalisation dans l'année suivant leur naissance des prématurés d'âge gestationnel inférieur ou égal à 32 semaines d'aménorrhée. Comparaison de 2 cohortes: 1997 et 2002. Arch Pediatr. 2005;12:1462-1470.

20. Escobar GJ, Greene JD, Hulac P, Kincannon E, Bischoff K, Gardner MN, et al. Rehospitalisation after birth hospitalisation: Patterns among infants of all gestations. Arch Dis Child. 2005;90:125-31.

21. Stensvold HJ, Klingenberg C, Stoen R, Moster D, Braekke K, Guthe HJ, et al. Neonatal morbidity and 1 -year survival of extremely preterm infants. Pediatrics. 2017;139:e20161821

22. Fellman $V$, Hellström-Westas $L$, Norman M., Westgren $M$, Källén $K$, Lagercrantz $H$, et al. One-year survival of extremely preterm infants after active perinatal care in Sweden. J Am Med Assoc. 2009;301:2225-2233.

23. Doyle LW, Ford G, Davis N. Health and hospitalisations after discharge in extremely low birth weight infants. Semin Neonatol. 2003;8:137-145

24. Pramana IA, Latzin P, Schlapbach LJ, Hafen G, Kuehni CE, Nelle $M$, et al. Respiratory symptoms in preterm infants: Burden of disease in the first year of life. Eur J Med Res. 2011;16:223-230.

25. Escobar GJ, Joffe S, Gardner MN, Armstrong MA, Folck BF, Carpenter DM. Rehospitalization in the first two weeks after discharge from the neonatal intensive care unit. Pediatrics. 1999; 104:e2

26. Islam JY, Keller RL, Aschner JL, Hartert TV, Moore PE. Understanding the short- and long-term respiratory outcomes of prematurity and bronchopulmonary dysplasia. Am J Respir Crit Care Med. 2015;192:134-156.

27. Marret S, Chollat C, de Quelen R, Cardoso GP, Abily-Donval $\mathrm{L}$, Chadie A, et al. Parcours et développement neurologique et comportemental de I'enfant prématuré. Arch Pediatr. $2015 ; 22: 195-202$.

28. Swamy GK, Østbye T, Skjærven R. Association of preterm birth with long-term survival, reproduction, and next-generation preterm birth. J Am Med Assoc. 2008; 299:1429-1436.

29. Ballot DE, Chirwa TF, Cooper PA. Determinants of survival in very low birth weight neonates in a public sector hospital in Johannesburg. BMC Pediatr. 2010;10:1-11. 